\section{O MONITORAMENTO DA VAZÃO COMO FERRAMENTA PARA O PLANO DE GESTÃO AMBIENTAL EM MICROBACIAS HIDROGRÁFICAS}

\author{
Mariana Bárbara Lopes Simedo ${ }^{1}$ \\ Antonio Lucio Mello Martins ${ }^{2}$ \\ Maria Conceição Lopes ${ }^{3}$
}

\begin{abstract}
RESUMO
Quando nos referimos à temática do planejamento ambiental, uma das formas de estudos constitui em pesquisas aplicadas em bacias hidrográficas para instituir o plano de gestão ambiental em microbacias. Estudos comprovam que é fundamental o manejo e a manutenção dos recursos hídricos para garantia de sua disponibilidade, e que o monitoramento da vazão de um curso de água é importante e indispensável para quantificar o volume de água em uma determinada bacia. Nesse contexto os objetivos deste trabalho são: avaliar os dados quantitativos da vazão na microbacia do Córrego da Olaria, Pindorama - SP, e utilizar o monitoramento da vazão como subsídio no plano de gestão dos recursos hídricos. Realizou-se o monitoramento mensal da vazão com uso de linígrafo (Teledyne Isco - 2150) nos quatro pontos principais de contribuição na microbacia. Os resultados foram submetidos à análise estatística, avaliando a vazão e a interação com as nascentes e a época (seca ou chuvosa), e realizou-se gráficos temporais da vazão correlacionando-os com dados pluviométricos. Os dados obtidos permitem concluir que as nascentes em mata nativa apresentam maior vazão, enquanto que a nascente em área de mata não consolidada a menor vazão. $O$ monitoramento da vazão demonstra ser uma importante ferramenta para elaboração no plano de gestão ambiental em bacia hidrográfica.
\end{abstract}

PALAVRAS-CHAVE: Vazão. Gestão dos Recursos Hídricos. Uso do Solo.

\section{MONITORING THE FLOW AS A TOOL FOR THE PLAN OF ENVIRONMENTAL MANAGEMENT IN RIVER BASINS}

\begin{abstract}
When we refer to the theme of environmental planning, one way of studies is in applied research in river basins to institute the environmental management plan in watersheds. Studies show that it is essential the management and maintenance of water resources to guarantee their availability, and monitoring the flow of a stream is important and necessary to quantify the volume of water in a particular basin. In this context the objectives of this study are to evaluate the quantity of data flow in the watershed Pottery Stream, Pindorama - SP, use and monitoring the flow as an aid in the management plan of water resources. Held monthly monitoring the flow with the use of linígrafo
\end{abstract}

\footnotetext{
${ }^{1}$ Tecnóloga em Agronegócio, Mestranda em Agronomia, Programa Ciência do Solo na FCAVUNESP. mariana blopes@hotmail.com

${ }^{2}$ Engenheiro Agrônomo, Dr., Pesquisador Científico VI na APTA - Polo Regional Centro Norte. Imartins@apta.sp.gov.br

${ }^{3}$ Bióloga, mestre em Agronomia, Ciência do Solo. Oficial de ApCT, APTA - Polo Regional Centro Norte.conceicao@apta.sp.gov.br
} 
(Teledyne Isco - 2150) in the four main points of contribution in the watershed. The results were statistically analyzed by assessing the flow and interaction with the springs and the time (dry or wet), and time took place the flow charts correlating them with rainfall data. The data support the conclusion that the sources in native forests have higher flow, while the spring in forest area unconsolidated a smaller flow. Monitoring the flow proves to be an important tool for developing the environmental management plan for the watershed.

KEYWORDS: Flow. Water Resources Management. Land Use.

\section{SEGUIMIENTO DEL FLUJO COMO HERRAMIENTA PARA EL PLAN DE GESTIÓN AMBIENTAL EM CUENCAS}

\begin{abstract}
RESUMEN
Cuando nos referimos al tema de la planificación ambiental, una forma de estudios es en la investigación aplicada en las cuencas hidrográficas de instituir el plan de gestión ambiental en las cuencas hidrográficas. Los estudios demuestran que es esencial la gestión y mantenimiento de los recursos hídricos para garantizar su disponibilidad y supervisar el flujo de una corriente es importante y necesario cuantificar el volumen de agua en una cuenca determinada. En este contexto, los objetivos de este estudio son evaluar la cantidad de flujo de datos en el flujo de la cerámica cuenca, Pindorama - SP, el uso y el control de la circulación como una ayuda en el plan de gestión de los recursos hídricos. Celebrada el seguimiento mensual de la corriente con el uso de linígrafo (Teledyne Isco - 2150) en los cuatro puntos principales de aporte en la cuenca. Los resultados fueron analizados estadísticamente mediante la evaluación del flujo y la interacción con los muelles y el tiempo (seco o húmedo), y el tiempo se llevaron a cabo los diagramas de flujo que correlacionan con datos de precipitación. Los datos apoyan la conclusión de que las fuentes en los bosques nativos tienen mayor caudal, mientras que el resorte de la superficie forestal no consolidada de un flujo menor. Seguimiento del flujo resulta ser una herramienta importante para el desarrollo del plan de gestión ambiental para la cuenca.
\end{abstract}

PALABRAS CLAVE: Flujo. Gestión de los Recursos Hídricos. Uso Del Suelo.

\section{INTRODUÇÃO}

Quando nos referimos à temática do planejamento ambiental, uma das formas de estudos são pesquisas aplicadas em bacias hidrográficas como ferramentas para constituir o plano de gestão ambiental em microbacias. Segundo Albuquerque (2012), é importante contextualizar a valor do uso e aplicação desta unidade nas questões associadas a três parâmetros expostos a seguir:

1. A delimitação da área e o reconhecimento do ambiente físico da bacia como visão estratégica do planejamento.

2. A bacia como célula de análise integrada, que permite a conexão entre a organização espacial dos grupos sociais e os aspectos do ambiente físico.

3. A aplicabilidade de legislação específica, para esta unidade hidrográfica quanto à gestão e gerenciamento. 
Para Rodrigues (2013), a necessidade de estudar o ambiente é preponderante no que se refere aos recursos naturais como solo, vegetação e hidrografia, pois o ambiente de uma determinada região deve ser reconhecido e monitorado para manter os níveis de qualidades ambientais desejados.

A bacia hidrográfica é uma importante unidade de estudo e planejamento, devido ao fato desta ser uma unidade geográfica onde os recursos naturais se integram, constituindo uma área de fácil reconhecimento e caracterização. É fundamental o manejo e a manutenção dos recursos hídricos para garantia de sua disponibilidade.

O uso de microbacias hidrográficas como unidades territoriais para o desenvolvimento de trabalhos experimentais é de suma importância. As pesquisas em bacias hidrográficas teve início por volta do começo deste século em vários países, e inúmeros resultados já obtidos mostram que o uso da terra e as atividades florestais podem afetar, não apenas a quantidade e a qualidade da água, como também, o regime de vazão do recurso hídrico (LOPES, 2011).

O escoamento superficial é um dos processos do ciclo hidrológico, que se forma pelo fluxo de água superficial, formando os canais de drenagem. Uma das grandezas desse escoamento é a vazão, que é conceituada como o volume de água escoado por unidade de tempo. Os valores obtidos de vazão em uma bacia hidrográfica auxiliam na previsão de enchentes e dimensionamento de empreendimentos hidráulicos, sendo de suma importância na elaboração de projetos que minimizam o impacto ambiental no que tange ao recurso hídrico.

Segundo Pinheiro et al. (2011), os cursos d'água refletem as consequências do uso e ocupação do solo na bacia hidrográfica. A irregularidade da distribuição temporal das chuvas e a degradação ambiental dos recursos naturais de uma bacia podem comprometer as reservas superficiais e subterrâneas.

Conforme descreve Tucci (2002), a ação do homem sobre o uso e ocupação do solo pode produzir impactos nos processos hidrológicos terrestres, como a redução ou aumento da vazão média, máxima e mínima e alterações na qualidade da água de uma bacia hidrográfica. Segundo Barbosa et al. (2005), a avaliação da demanda frente à disponibilidade de água na bacia é baseado no planejamento, controle e proteção dos recursos hídricos. Portanto a disponibilidade hídrica precisa ser bem conhecida para que haja uma gestão adequada nas atividades de 
administração. Essa disponibilidade é avaliada através da aplicação de um balanço hídrico, sendo imprescindível o conhecimento das principais variáveis hidrológicas, notadamente da precipitação e da vazão.

A medida da vazão de uma nascente é um parâmetro muito importante para caracterizar o seu regime hidrológico, cujo comportamento é influenciado pelo índice pluviométrico, por sua localização e pela ação do homem sobre as condições naturais da região (ARAÚJO FILHO, et al., 2011).

O monitoramento da vazão de um curso de água é importante e indispensável para quantificar o volume de água em uma determinada bacia. As diversas atividades desenvolvidas em bacias hidrográficas com alteração do uso e ocupação do solo interferem diretamente no regime temporal e espacial da vazão.

Nesse contexto os objetivos deste trabalho são: avaliar os dados quantitativos da vazão na microbacia do Córrego da Olaria, correlacionando-a com o uso e a ocupação do solo e utilizar o monitoramento da vazão como subsídio no plano de gestão dos recursos hídricos.

\section{METODOLOGIA}

\section{1 Área de Estudo}

O local proposto para realização do presente estudo é a microbacia hidrográfica do Córrego da Olaria, situada no Polo Regional Centro Norte, pertencente à Agência Paulista de Tecnologia dos Agronegócios (APTA), órgão vinculado a Secretaria da Agricultura e Abastecimento (SAA), localizado no município de Pindorama, SP. Apresenta extensão aproximada de 9,17km², entre altitudes de $410 \mathrm{~m}$ e $740 \mathrm{~m}$, é balizada entre as coordenadas UTM, zona $22 \mathrm{~K}$, e as coordenadas geográficas: entre as latitudes $21^{\circ} 05^{\prime} 47,80^{\prime \prime} S$ e $21^{\circ} 19^{\prime} 35,93$ " S; e longitudes $49^{\circ} 03^{\prime}$ 02,88" W e $48^{\circ} 42^{\prime} 52,27^{\prime \prime}$ W. O planalto é ondulado levemente ondulado e contém em suas cabeceiras pequenos córregos formadores da rede hidrográfica regional, (Figura 1). A Microbacia do Córrego da Olaria foi selecionada para este estudo, tendo em vista ser de grande importância na área de drenagem da sub-bacia do rio São Domingos apresentando a vazão de contribuição com parte dos municípios paulistas de Pindorama, Catanduva, Catiguá, Tabapuã, Cedral e 
Uchoa, e ainda, por apresentar áreas agricultáveis com significativa atividade socioeconômica na região noroeste do Estado de São Paulo.

O Polo Regional Centro Norte possui uma área territorial de 532,8 ha, sendo que aproximadamente 120 ha são de mata nativa divididas em três fragmentos. $O$ clima enquadra-se, segundo a classificação climática de Köppen, como o Aw, definido como clima tropical úmido com estação chuvosa no verão e seca no inverno. Apresenta temperatura média anual de $22,8^{\circ} \mathrm{C}$, e umidade relativa média anual de $71,6 \%$.

O balanço hídrico anual segundo a metodologia de Thornthwaite \& Mather (1955), caracteriza climaticamente o local como precipitação de $1389 \mathrm{~mm}$, evapotranspiração potencial de 1117,6 mm, evapotranspiração real de 909,9 mm, deficiência hídrica de 207,6 mm e excedente hídrico de 480,1 mm.

Figura 1: Rede Hidrográfica da Microbacia do Córrego da Olaria, Pindorama, SP

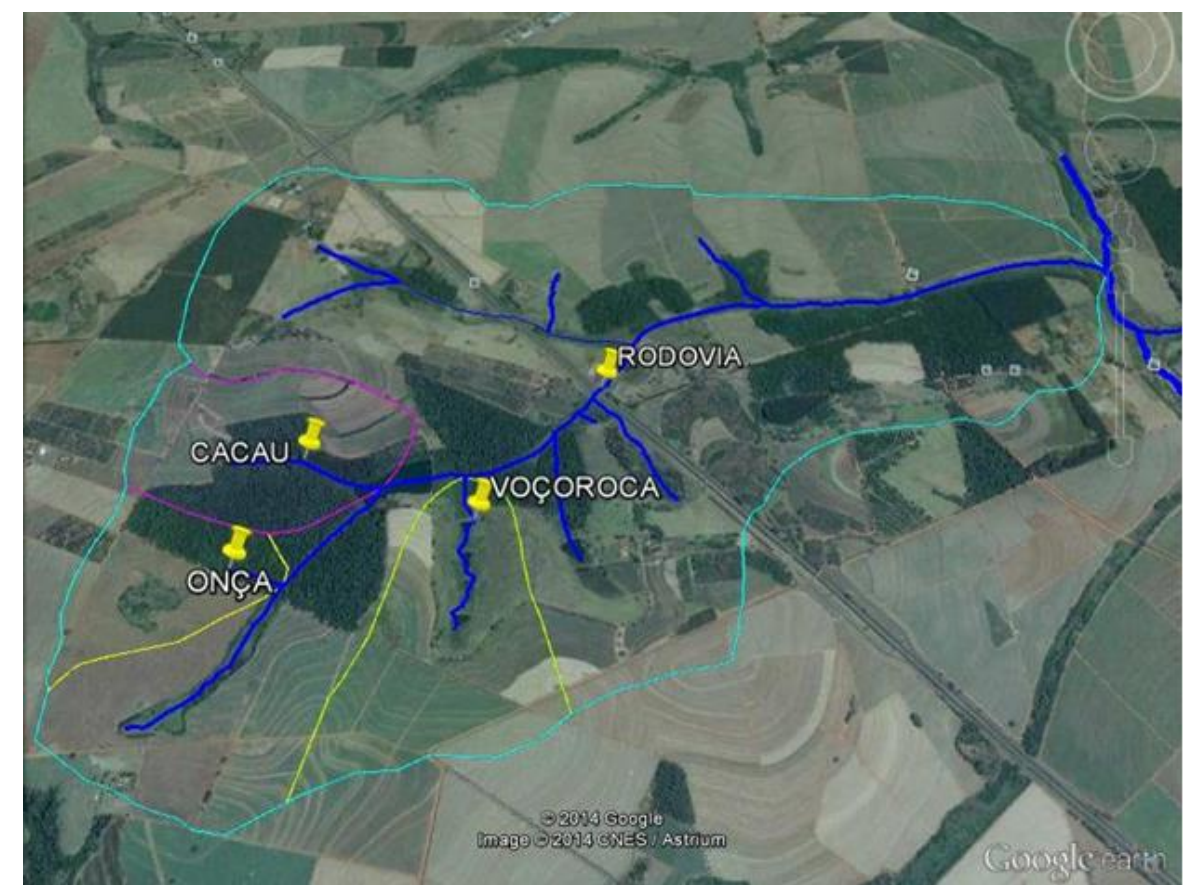

Fonte: GOOGLE EARTH, 2014. 


\section{Caracterização Morfométrica, Monitoramento da Vazão, e Análise Estatística das Microbacias do Córrego da Olaria}

Para iniciar o estudo, a microbacia do Córrego da Olaria foi dividida em subbacias baseado em seus divisores topográficos internos, e assim cada sub-bacia foi analisada individualmente. Para medir a vazão foram selecionados quatro pontos principais de contribuição na microbacia, (Figura 1). Cada ponto monitorado possui características específicas, as quais estão descritas na tabela 1 abaixo:

Tabela 1: Características dos pontos de medição da vazão na microbacia do Córrego da Olaria, município de Pindorama, SP

\begin{tabular}{|c|c|}
\hline Pontos & Uso e Ocupação do Solo \\
\hline P1 - Nascente Onça & Nascente localizada em mata nativa. \\
\hline P2 - Nascente Cacau & Nascente localizada em mata nativa com marcante presença de \\
serapilheira.
\end{tabular}

Fonte: RELATÓRIO FAPESP, 2013

A análise morfométrica dos pontos de vazão das microbacias está demonstrada na tabela 2 abaixo:

Tabela 2: Dados da análise morfométrica dos pontos de vazão da microbacia do Córrego da Olaria, Pindorama, SP

\begin{tabular}{|c|c|c|c|c|c|}
\hline $\begin{array}{c}\text { Pontos } \\
\text { Vazão }\end{array}$ & $\begin{array}{c}\text { Oeste } \\
\text { Longitude }\end{array}$ & $\begin{array}{c}\text { Norte } \\
\text { Latitude }\end{array}$ & $\begin{array}{c}\text { Altitude } \\
(\mathbf{M})\end{array}$ & $\begin{array}{c}\text { Área } \\
\left(\mathbf{K M}^{2}\right)\end{array}$ & Perímetro \\
\hline VOÇOROCA & 715460,87 & 7651416,71 & 547 & 7,5474 & 4102,8179 \\
\hline RODOVIA & 716018.27 & 7651957.29 & 531 & 34,4118 & 9177086,7464 \\
\hline CACAU & 714670,17 & 7651662,13 & 578 & 6,8104 & 3339,5972 \\
\hline ONÇA & 714542,44 & 7651174,31 & 584 & 3,8486 & 2588,2578 \\
\hline
\end{tabular}




\section{Periódica Eletrânica

Fonte: RELATÓRIO FAPESP, 2013

O monitoramento da vazão das microbacias foi realizado mensalmente no período de outubro de 2013 a setembro de 2014, com uso do aparelho linígrafo (Teledyne Isco - 2150), o qual permite a medição dos parâmetros, a saber: vazão $(\mathrm{l} / \mathrm{s})$, vazão total $(\mathrm{m} 3)$, velocidade $(\mathrm{m} / \mathrm{s})$ e nível $(\mathrm{m})$ da água. Este utiliza a tecnologia de comprimento de onda contínua Doppler para medir a velocidade média do fluxo, sendo que o sensor emite um onda ultrassônica contínua, desta forma ele é capaz de medir a freqüência enviada através do retorno (eco) refletido pela bolhas de ar e partículas encaminhadas pelo fluxo. A vazão é calculada com fórmula específica, independentes de nível e área, e a seção é determinada no programa digitando a medida da largura podendo ser consideradas como seção canais - redondos, em formato de $U$, retangulares, trapezoidais, elípticos. Abaixo na figura 2 é ilustrada a leitura da vazão realizada com o linígrafo.

Figura 2: Realização da leitura da vazão com linígrafo (Teledyne Isco - 2150)
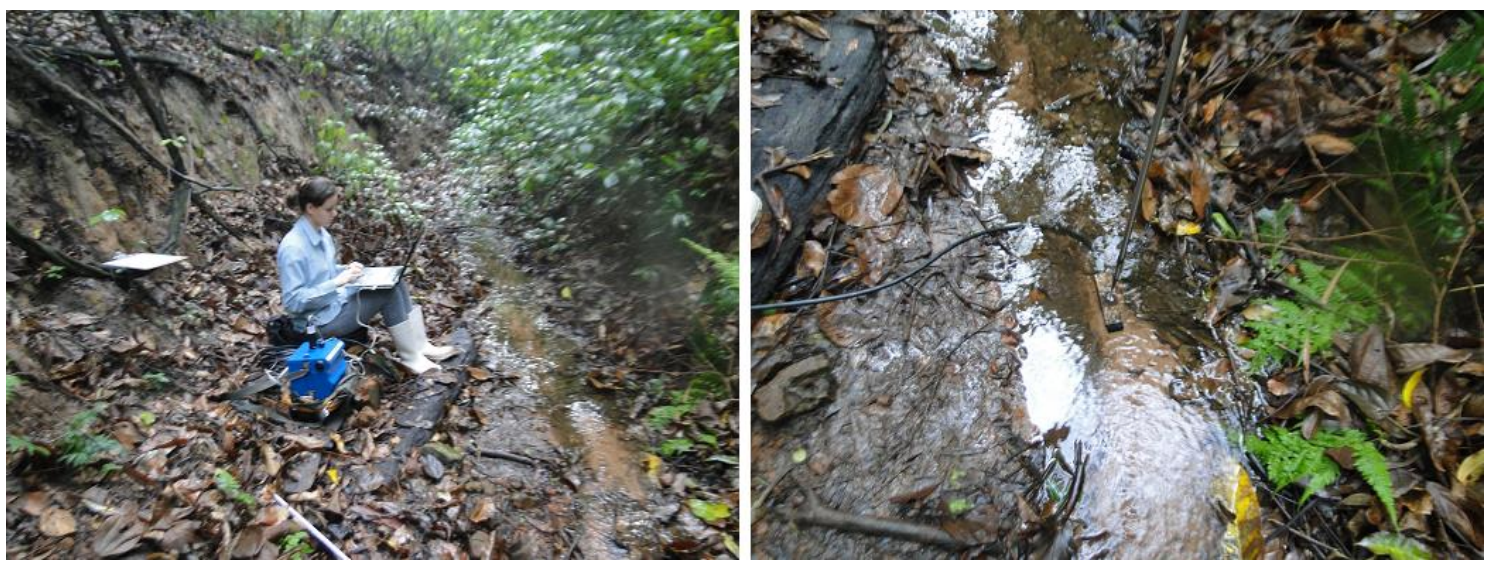

Fonte: RELATÓRIO FAPESP, 2013.

Os resultados obtidos pelo linígrafo foram submetidos à análise estatística, com o propósito de avaliar a vazão coletada e a interação com as nascentes, e a vazão coletada e a interação com a época (seca ou chuvosa). A análise estatística dos dados foi elaborada no software MINITAB. O delineamento estatístico foi inteiramente casualizado (DIC). A análise de variância foi empregada usando o teste de Tukey 5\%, no programa SAS (Versão 6.11).

Além disso, elaborou-se gráficos temporais com os dados quantitativos da vazão de cada ponto avaliado da microbacia de todo o período, correlacionando-os 
com dados pluviométricos e com o uso e ocupação do solo. Os dados de precipitação pluviométrica foram coletados na Estação Meteorológica Automática (EMA) instalada no Polo Regional Centro Norte (APTA), e processados pelo sistema do Centro Integrado de Informações Agrometeorológicas (CIIAGRO), o qual disponibiliza os dados diários por local.

\section{RESULTADOS}

\subsection{Gráficos Temporais}

A vazão estimada da microbacia do Córrego da Olaria variou de 0,03005 l/s a $17,54509524 \mathrm{l} / \mathrm{s}$, durante o período de novembro de 2013 a setembro de 2014 . Quanto à pluviometria destaca-se como maior precipitação o mês de março de 2014 com 176,2 mm e a menor no mês de agosto com $0 \mathrm{~mm}$. Abaixo demonstra - se os gráficos de resultados de cada ponto da microbacia com as médias da vazão (I/s) obtidas pelo linígrafo, e a correlação com os dados pluviométricos.

Figura 3: Médias da vazão (I/s) obtidas pelo linígrafo na nascente Onça, correlacionado com os dados pluviométricos no período de outubro de 2013 a setembro de 2014

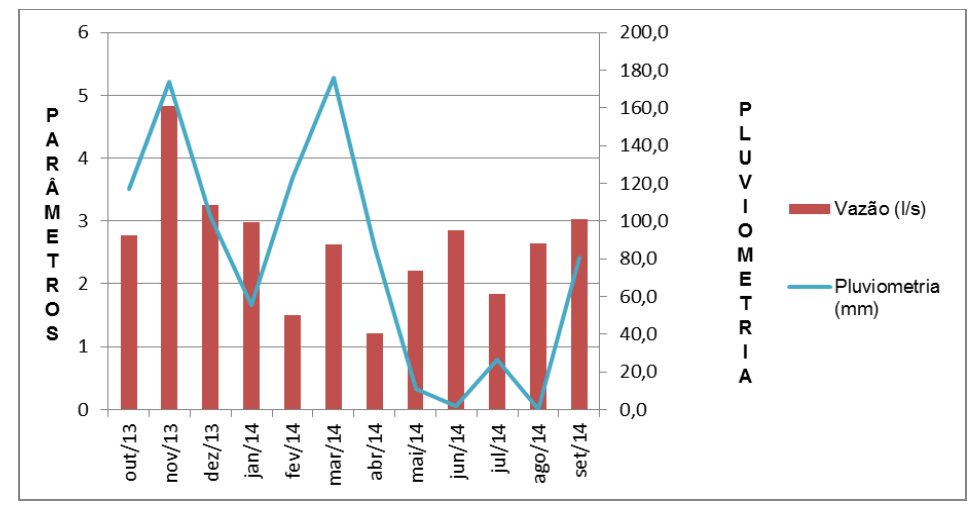

Fonte: RELATÓRIO FAPESP, 2013.

O ponto um: nascente onça obteve o maior resultado de vazão no mês de novembro de 2013 com 4,8 l/s e a menor vazão no mês de fevereiro de 2014 com 1,5 I/s. As precipitações desses meses corresponderam a 173,7 mm e 123,1 $\mathrm{mm}$.

Observou-se que os resultados durante o período analisado não oscilaram significativamente, sendo o ponto que manteve a vazão durante os meses com baixa precipitação. O que garantiu essa disponibilidade hídrica foi o fato dessa nascente estar presente em mata nativa consolidada, além de ser classificada como perene. 
A zona ripária que inclui a mata ciliar constitui um ecossistema que desempenha um dos mais importantes serviços ambientais: a manutenção dos recursos hídricos em termos de qualidade e quantidade, sendo fundamental para garantir a disponibilidade de água para os múltiplos usos, e para a gestão atual destes recursos (LIMA \& ZAKIA, 2000). De acordo com Oliveira et al. (2011), as matas ciliares podem gerar benefícios diretos e indiretos aos recursos hídricos, além da sua estabilização e permanência.

Segundo Poleto et al. (2010), o mau uso do solo e a ausência de matas ciliares são os principais fatores que favorecem o assoreamento dos mananciais, assim, sua conservação favorece a qualidade das águas servindo como agente regulador de vazão fluvial e, consequentemente, de cheias, na dissipação de energia erosiva das águas de chuvas e pluviais e local de refúgio e fonte de alimentos à fauna.

A vazão, segundo Valente \& Gomes (2005), pode ser classificada pela persistência de seus fluxos, em: perenes que se manifestam durante o ano todo, apresentando variação na vazão ao longo do ano; Intermitentes que fluem durante a estação chuvosa, mas secam durante parte do ano (estação seca); temporárias que ocorre somente em resposta direta a precipitação, e nascente difusa resultante dos afloramentos de água, proveniente de lençóis freáticos, que acumulam água até dar início a fluxos contínuos.

Figura 4: Médias da vazão (I/s) obtidas pelo linígrafo na nascente Cacau, correlacionado com os dados pluviométricos, no período de outubro de 2013 a setembro de2014

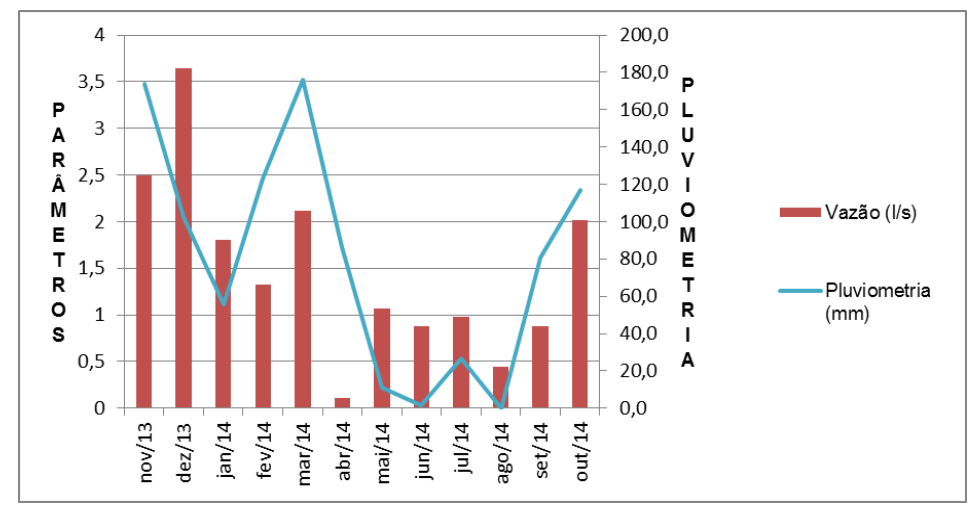

Fonte: RELATÓRIO FAPESP, 2013. 
O ponto dois: nascente cacau obteve o maior resultado de vazão no mês de dezembro de 2013 com 3,6 l/s e a menor vazão no mês de agosto de 2014 com 0,44 I/s. As precipitações desses meses corresponderam a 102,3 mm e $0 \mathrm{~mm}$.

Esse ponto é localizado em mata nativa e possui como característica permanente o excesso de serrapilheira na área ao redor e no canal da passagem de água para leitura. Observou-se que os meses de maior e menor resultado de vazão corresponderam à quantidade de precipitação recebida. Essa nascente é classificada como perene.

A água do escoamento superficial é retida e absorvida pela serrapilheira (formada pelo acúmulo de material vegetal depositado sobre o solo), que exerce uma função de esponja, auxiliando a infiltração da água e a sua retenção no solo, e reduzindo as enxurradas. A taxa de infiltração de água em solos florestais pode ser de 10 a 15 vezes maior do que em pastagem e 40 vezes mais que em um solo desprovido de vegetação (DAVIDE et al., 2000).

Figura 5: Médias da vazão (1/s) nascente Voçoroca, correlacionado com os dados pluviométricos, no período de outubro de 2013 a setembro de 2014

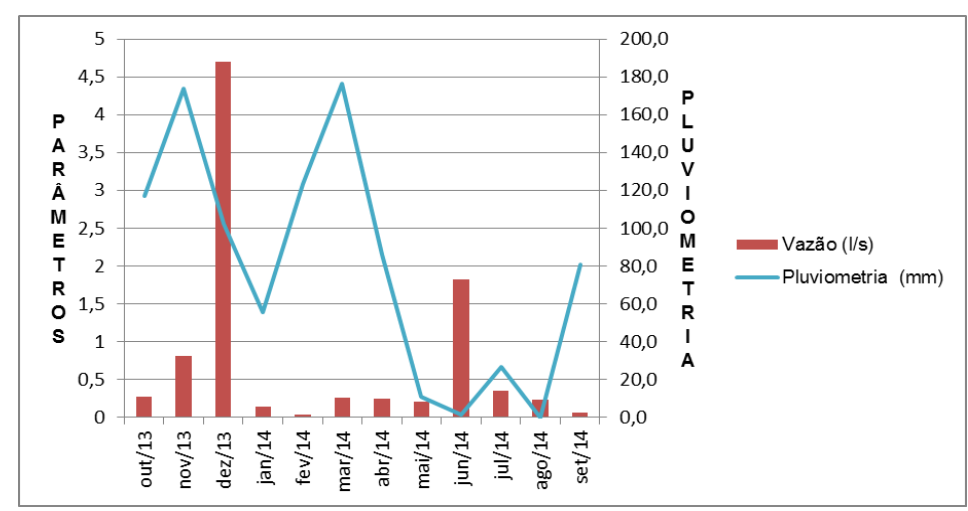

Fonte: RELATÓRIO FAPESP, 2013.

O ponto três: nascente voçoroca obteve o maior resultado de vazão no mês de dezembro de $2013 \mathrm{com} 4,7 \mathrm{l} / \mathrm{s}$ e a menor vazão no mês de fevereiro de $2014 \mathrm{com}$ $0,03 \mathrm{l} / \mathrm{s}$. As precipitações desses meses corresponderam a 102,3 mm e 123,1 mm.

Essa nascente é classificada como perene, e localiza-se em uma área recuperada por prática de conservação de solo, onde há quatro açudes artificiais em desnível e interligados com canais escoadouros de concreto, que possibilitam a passagem da água no local a uma velocidade controlada. Além disso, ressalta-se que houve em 2011 a implantação de mata ciliar e uso de Sistema Agroflorestal 
(SAF) ao redor de todos os açudes, sendo que essa floresta ainda não se encontra consolidada.

Uma característica eminente nesse ponto é o excesso de macrófitas aquáticas pertencentes aos gêneros Salvinia, Eichhornia (aguapé) e Nymphaea nos açudes, sendo de maior frequência no açude três e quatro. Observou-se que no período de janeiro a maio de 2014 houve a redução significativa da vazão, ainda sendo no período de chuva. O excesso de macrófitas diminui a velocidade e o fluxo da água, e interferem na leitura da vazão, que nesse ponto é realizada no canal escoadouro do quarto açude.

A ausência de mata ciliar favorece a degradação dos recursos hídricos aumentando os sedimentos carreados e consequentemente a proliferação de plantas aquáticas, que é comum nos mananciais. (SANTOS et al. 2012).

A partir do mês de maio de 2014 foi realizada a limpeza manual das plantas aquáticas, para impedir a obstrução do canal, e não haver interferência nos resultados obtidos pelo linígrafo. Durante o período analisado, foi observado que esse ponto mostra a menor vazão da microbacia, e isso se deve ao fato de esta nascente não estar localizada em uma área com floresta consolidada.

Segundo Latuf (2007), com o solo mais exposto o mesmo ficará mais susceptível as ações da energia cinética associada a precipitações e, consequentemente, a capacidade de infiltração tenderá a ficar reduzida, acarretando no aumento do escoamento superficial e das vazões máximas e medias e reduzindo as vazões mínimas.

Figura 6: Médias da vazão (I/s) obtidas pelo linígrafo na Foz Rodovia, correlacionado com os dados pluviométricos, no período de outubro de 2013 a setembro de 2014

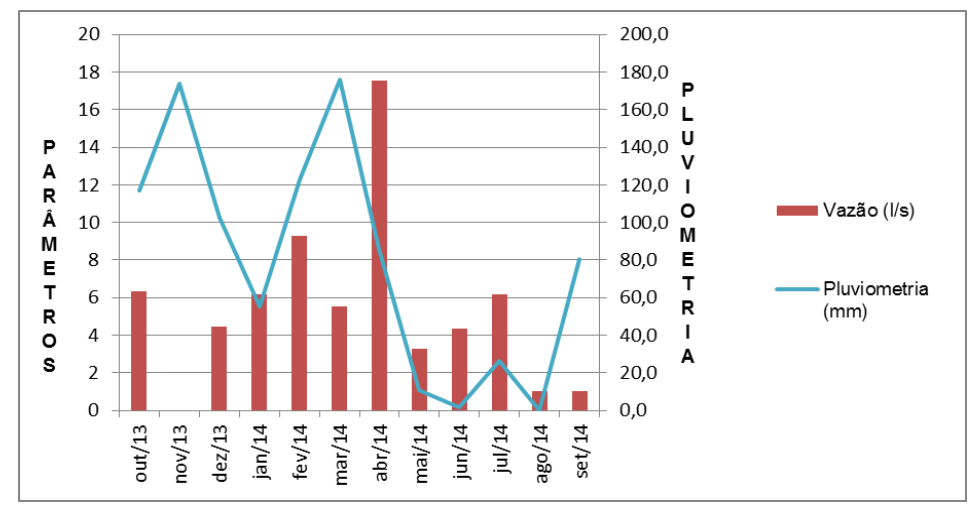

Fonte: RELATÓRIO FAPESP, 2013. 
O ponto quatro: rodovia obteve o maior resultado de vazão no mês de abril de $2014 \mathrm{com} \mathrm{17,5} \mathrm{l/s} \mathrm{e} \mathrm{a} \mathrm{menor} \mathrm{vazão} \mathrm{no} \mathrm{mês} \mathrm{de} \mathrm{setembro/2014} \mathrm{com} \mathrm{1,5} \mathrm{l/s.} \mathrm{As}$ precipitações desses meses corresponderam a $86,1 \mathrm{~mm}$ e $80,5 \mathrm{~mm}$.

Esse ponto é a foz do córrego da olaria, e possui como características o excesso de plantas aquáticas e matéria orgânica dissolvida na água, o que dificulta a leitura da vazão com linígrafo. Observou-se que há resultados significativos menores no mês de agosto e setembro de 2014. Além da ausência da precipitação no mês de agosto, detectou-se que o que colaborou para a diminuição expressiva da vazão foi a presença de animais na várzea antes desse ponto, $70 \mathrm{~m}$ acima. Os animais estavam dentro dessa várzea, pisoteando taboas e outras plantas aquáticas, e consequentemente aumentando à presença de matéria orgânica na água, e obstruindo a passagem de água no canal da leitura.

Esse ponto representa toda contribuição à rede de drenagem a montante. Dado que todo o escoamento das águas superficiais convergirá, necessariamente, para a extremidade inferior (confluência ou foz) do segmento da hidrografia, percebe-se também que existe uma associação natural entre a área de drenagem e seu exutório (RIBEIRO et al., 2008).

\section{2 Estatística}

A análise estatística da vazão coletada e a interação com as nascentes, e a vazão coletada e a interação com a época (seca ou chuvosa), resultou-se em significativo segundo análise de variância e teste de Tukey $5 \%$, conforme se observa nas tabelas 3 e 4 abaixo:

Tabela 3: Vazão coletada e a interação com época

\begin{tabular}{|c|c|c|c|}
\hline Variável & Época & $\begin{array}{l}\text { Valor } \\
\text { médio }\end{array}$ & $\begin{array}{l}\text { Desvio } \\
\text { padrão }\end{array}$ \\
\hline Vazão $\left.{ }^{* *}\right)$ & 1 (seca) & $\begin{array}{c}1,603 \\
a\end{array}$ & 1,205 \\
\hline Vazão $\left(^{* *}\right)$ & $\begin{array}{c}2 \\
\text { (chuvosa) }\end{array}$ & $\begin{array}{c}2,633 \\
b\end{array}$ & 1,813 \\
\hline \multicolumn{4}{|c|}{$\left({ }^{* *}\right)$ significativo segundo análise de variância para $p<0,001$} \\
\hline \multicolumn{4}{|c|}{ Letras diferentes no valor médio indicam diferença segundo Tukey $5 \%$} \\
\hline
\end{tabular}

Fonte: RELATÓRIO FAPESP, 2013 
Tabela 4: Vazão coletada e a interação com as nascentes

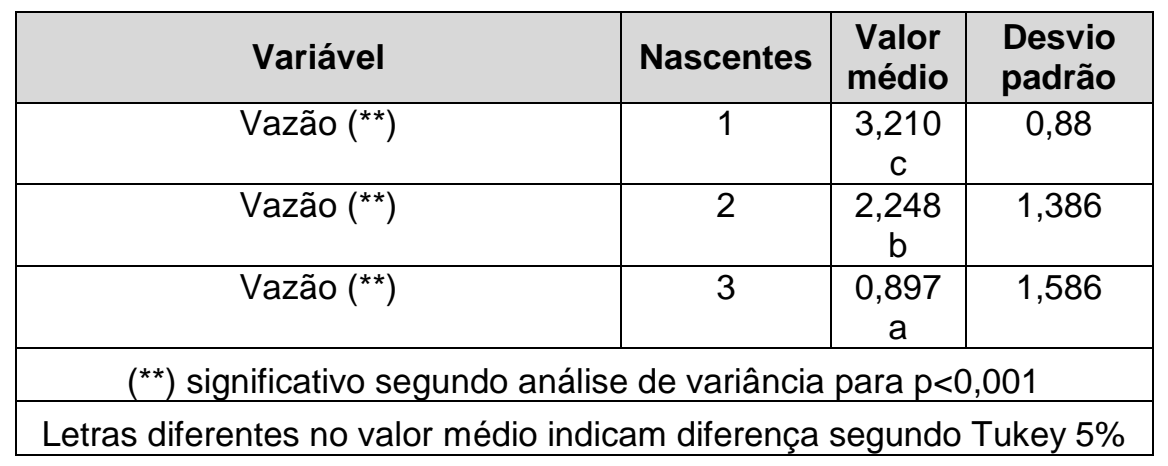

Fonte: RELATÓRIO FAPESP, 2013

A nascente três: voçoroca, onde há ausência de mata consolidada apresentou menor valor médio de vazão segundo teste de Tukey $5 \%$, confirmando os resultados do gráfico temporal (Figura 5).

As nascentes um e dois: onça e cacau, com presença de matas consolidadas apresentaram maiores valores de vazão segundo teste de Tukey $5 \%$, confirmando mais uma vez os resultados dos gráficos temporais apresentados (Figuras 3 e 4 ).

\section{CONCLUSÕES}

Os dados obtidos permitem concluir que as nascentes em mata nativa apresentam maior vazão, enquanto que a nascente em área de mata não consolidada a menor vazão. O monitoramento da vazão demonstra ser uma importante ferramenta para elaboração no plano de gestão ambiental em bacia hidrográfica.

\section{AGRADECIMENTOS}

A Fundação de Amparo á Pesquisa do Estado de São Paulo (FAPESP) pelo apoio financeiro e institucional. 


\section{Periódica Eletrânica

\section{REFERÊNCIAS}

ALBUQUERQUE, A. R. da C. Bacia Hidrográfica: Unidade De Planejamento Ambiental. Revista Geonorte. Universidade Federal do Amazonas, 2012. Edição Especial, V.4, N.4, p.201.

ARAÚJO FILHO, P. F.; BRAGA, R. A. P.; GUSMÃO, P. T. R. Mensuração da vazão em nascentes do Assentamento Serra Grande na bacia do Rio Natuba - PE. Anais do XIII Congresso Nordestino de Ecologia. SNE, Recife, 2011.

BARBOSA, S. E. da Silva; Júnior, A. R. B.; Silva, G. Q.; Campos, E. N. B.; Rodrigues, V. de Carvalho. Geração de modelos de regionalização de vazões máximas, médias de longo período e mínimas de sete dias para a bacia do rio do Carmo, Minas Gerais. Engenharia Sanitária Ambiental, Rio de Janeiro, v.10, n.1, Março 2005. Disponível em: http://dx.doi.org/10.1590/S141341522005000100008. Acesso em 14 de maio de 2015.

DAVIDE, A. C.; FERREIRA, R. A.; FARIA, J. M. R.; BOTELHO, S. A. Restauração de matas ciliares. Informe agropecuário, Belo Horizonte, 2000. V. 21, n. 207, p. 65.

LATUF, M. O. Mudanças no Uso do Solo e Comportamento Hidrológico nas Bacias do Rio Preto e Ribeirão entre Ribeiros. 2007, 151p. Dissertação (Mestrado em Engenharia Agrícola), Universidade Federal de Viçosa, Minas Gerais, 2007.

LIMA, W.P.; ZAKIA, M.J.B. Hidrologia de matas ciliares. In: RODRIGUES, R.R.; LEITÃO FILHO, H.F. Matas ciliares: conservação e recuperação. São Paulo: EDUSP/ Fapesp, 2000. cap.3, p.33-44.

LOPES, M. C. Ações de Educação Ambiental e Monitoramento da Água no Córrego da Olaria, Apta-Pindorama, SP. Dissertação de Mestrado, Curso de Agronomia, Programa de Pós- Graduação em Ciência do Solo, Universidade Paulista de São Paulo, UNESP - Jaboticabal-SP, 2011. 64 p.

OLIVEIRA, L. C. de; PEREIRA, R.; VIEIRA, J. R. G. Análise da degradação ambiental da mata ciliar em um trecho do rio Maxaranguape, RN: Uma contribuição à gestão dos recursos hídricos do Rio Grande do Norte - Brasil. Holos Environment, 2011. v.5, p.49-66.

PINHEIRO, R. C., TONELLO, K. T., VALENTE, R. O. A., MINGOTI, R., SANTOS, I. P. OCUPAÇÃO E CARACTERIZAÇÃO HIDROLÓGICA DA MICROBACIA DO CÓRREGO IPANEMINHA, SOROCABA-SP. Revista Irriga. Botucatu, 2011. v. 16, n. 3, p. 234-245.

RELATÓRIO TÉCNICO CIENTÍFICO DO PROJETO FAPESP 2013/11932-1. Monitoramento dos Recursos Hídricos para Avaliação das Alterações Associadas ao Uso e Manejo do Solo da Microbacia Hidrografica do Córrego da Olaria. APTA - Polo Regional Centro Norte, Pindorama, SP, 2014.

RIBEIRO, C. A. A. S.; SOARES, V. P.; SANTOS, SOARES; R. M., Boechat, C. P. Estruturação topológica de grandes bases de dados de bacias hidrográficas. Revista Árvore. 2008, vol.32, n.4, pp. 687-696.

RODRIGUES, F. M. Caracterização ambiental da bacia hidrográfica do Córrego Rico, Jaboticabal - SP. Tese de doutorado - Universidade Estadual Paulista Júlio de Mesquita Filho, UNESP - Jaboticabal-SP, 2013. 97 p. Disponível em: <http://hdl.handle.net/11449/105123>.

SANTOS, G. O.; HERNANDEZ, F. B. T. Uso do solo e monitoramento dos recursos hídricos no córrego do Ipê, llha Solteira, SP. Rev. brasileira eng. agríc. ambiental. Campina Grande, 2013. v. 17, n.1, p. 60-68. Disponível em: http://www.scielo.br/scielo.php?script=sci_arttext\&pid=S141543662013000100009. Acessado em 27 de maio de 2015.

THORNTHWAITE, C.W \& MATHER, J. R. The water balance. Centerton, New Jersey, Drexel Institute of Technology. 1955. 104p. (Publications in climatology, vol. 8, $n^{\circ} 1$ ). 
TUCCI, C. E. M. Impactos da variabilidade climática e uso do solo sobre os recursos hídricos. Brasília: Fórum Brasileiro de Mudanças Climáticas. 2002. 150p.

VALENTE, O. F.; GOMES, M. A. Conservação de nascentes: hidrologia e manejo de bacias hidrográficas de cabeceira. 1. ed. Viçosa-MG: Aprenda Fácil, 2005. 210p.

POLETO, C.; CARVALHO, S. L. de; MATSUMOTO, T. Avaliação da qualidade da água de uma microbacia hidrográfica no município de Ilha Solteira (SP). Revista Holos Environment. Rio Claro, SP, 2010. v.10, n. 1, p.106. 